\title{
Efficacy and prognosis of surgical treatment in ARMM and its effects on immune and inflammatory profiles
}

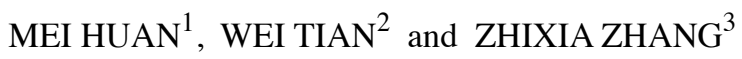 \\ ${ }^{1}$ Operating Room; ${ }^{2}$ Outpatient Department; ${ }^{3}$ Department of Breast Surgery, \\ Linyi Cancer Hospital, Linyi, Shandong 276000, P.R. China
}

Received December 2, 2019; Accepted August 18, 2020

DOI: $10.3892 /$ etm.2020.9407

\begin{abstract}
The aim of the present study was to investigate the efficacy and prognosis of surgical treatment in anorectal malignant melanoma (ARMM) as well as its effects on immune and inflammatory profiles. A total of 64 patients with ARMM were enrolled and divided into control group $(n=32)$ and observation group $(n=32)$ based on different therapeutic methods. Patients in the observation group underwent wide local excision, while those in the control group were given non-surgical treatment. The immune function was compared between the two groups after treatment. The expression levels of serum IL-17, IL-23 and vascular endothelial growth factor (VEGF) were compared between the groups before and after treatment. Patients were followed up for 5 years to observe the recurrence and survival rates in the two groups. Compared with those in the control group, the levels of cluster of differentiation $(\mathrm{CD}) 3^{+}, \mathrm{CD} 4^{+}$and $\mathrm{CD}^{+} / \mathrm{CD}^{+}$were increased, while the level of $\mathrm{CD}^{+}$was reduced in the observation group $(\mathrm{P}<0.05)$. The levels of serum IL-17, IL-23 and VEGF were significantly lower in both groups at 4, 6 and 8 weeks after treatment than those before treatment, and the decrease was more obvious in the observation group $(\mathrm{P}<0.05)$. The observation group exhibited a notably elevated 5-year survival rate and a remarkably decreased recurrence rate in comparison with the control group $(\mathrm{P}<0.05)$. For ARMM, surgical treatment is more effective than non-surgical treatment, which has less effect on immune function, is able to reduce serum IL-17, IL-23 and VEGF levels, lower recurrence rate, improve patient survival rate, and plays a certain positive role in prolonging the survival time of ARMM patients.
\end{abstract}

Correspondence to: Dr Zhixia Zhang, Department of Breast Surgery, Linyi Cancer Hospital, 6 Lingyuan East Street, Linyi, Shandong 276000, P.R. China

E-mail: zhangzhixia1972@163.com

Key words: rectal neoplasm, melanoma, surgery, prognosis, immunity, inflammation

\section{Introduction}

Anorectal malignant melanoma (ARMM), a fatal malignancy with high malignant degree and poor patient prognosis, has shown increasing incidence rate in recent years $(1,2)$. Since the clinical symptoms of ARMM patients are inapparent and non-specific, generally manifested as constipation, hematochezia, diarrhea, proctalgia and pruritus, most patients tend to be at the middle or advanced stage at diagnosis. In addition, ARMM is highly invasive, with frequent local and distant metastases. The 5-year survival rate of patients is relatively low $(3,4)$. As treatment for ARMM, radiotherapy, chemotherapy and surgical resection are adopted, of which surgical resection is usually considered the preferred option (5).

The dysfunction of immune system is closely related to the occurrence and development of malignant tumors (6). The proportion and function of $\mathrm{T}$ lymphocyte subsets can reflect the immune function $(6,7) . \mathrm{CD}^{+}$represents all $\mathrm{T}$ lymphocytes, $\mathrm{CD}^{+}{ }^{+}$represents helper $\mathrm{T}$ lymphocytes, $\mathrm{CD} 8^{+}$represents suppressive and cytotoxic T lymphocytes. Malignant tumors often manifest with a decrease of $\mathrm{CD}^{+}$and $\mathrm{CD} 4^{+}$lymphocytes, an increase of CD8 lymphocytes and a decrease of the CD4/CD8 ratio (7).

Inflammatory responses can participate in the development and progression of many malignant tumors. Interleukin-17 (IL-17) and IL-23 are cytokines that are abnormally expressed in various malignant tumors and participate in the development, progression and metastasis of such malignant tumors $(8,9)$. VEGF accelerates tumor angiogenesis, promotes tumor growth and increases tumor invasiveness, thus having a close relationship with metastasis (10).

In the present study, surgical treatment was adopted for ARMM, the prognosis was observed, the levels of $\mathrm{CD}^{+}, \mathrm{CD}^{+}$ and $\mathrm{CD} 4^{+} / \mathrm{CD}^{+}$was detected and expression of serum VEGF, IL-23 and IL-17 of patients were analyzed, to provide a basis for clinical treatment and prognosis evaluation.

\section{Patients and methods}

General data. A total of 64 ARMM patients treated in Linyi Cancer Hospital from July 2010 to June 2014 were selected as the subjects. Inclusion criteria: i) Patients meeting the diagnostic criteria for ARMM (11); ii) those with complete case data; and iii) those who signed an informed consent. 
Table I. General data of the subjects.

\begin{tabular}{lcccc}
\hline Item & Control group $(\mathrm{n}=32)$ & Observation group $(\mathrm{n}=32)$ & $\mathrm{t} / \chi^{2}$ & P-value \\
\hline Sex (male/female) & $13 / 19$ & $11 / 21$ & 0.063 & 0.802 \\
Age (years) & $35-75$ & $36-78$ & & \\
Average age (years) & $53.76 \pm 8.49$ & $54.35 \pm 8.58$ & 0.350 & 0.727 \\
BMI $\left(\mathrm{kg} / \mathrm{m}^{2}\right)$ & $22.65 \pm 1.57$ & $22.58 \pm 1.43$ & 1.030 & 0.305 \\
Clinical stage [n (\%)] & & & & \\
I-II & $15(46.87)$ & $14(43.75)$ & 0.012 & 0.922 \\
III-IV & $17(53.13)$ & $18(56.25)$ & & \\
\hline
\end{tabular}

Table II. Comparison of T lymphocyte subset levels between two groups of patients.

\begin{tabular}{lccccc}
\hline Group & $\mathrm{n}$ & $\mathrm{CD} 3^{+}$ & $\mathrm{CD}^{+}$ & $\mathrm{CD}^{+}$ & $\mathrm{CD}^{+} / \mathrm{CD}^{+}$ \\
\hline Observation group & 32 & $68.53 \pm 3.56$ & $40.83 \pm 3.56$ & $24.38 \pm 3.67$ & $1.85 \pm 0.47$ \\
Control group & 32 & $60.47 \pm 3.32$ & $36.47 \pm 3.74$ & $28.35 \pm 3.65$ & $1.39 \pm 0.35$ \\
$\mathrm{t}$ & & 5.503 & 2.974 & 2.664 & 2.895 \\
P-value & & $<0.0001$ & 0.003 & 0.009 & 0.004 \\
\hline
\end{tabular}

Exclusion criteria: i) Patients with mental disorder, or ii) those who refused to cooperate and had extremely low compliance. The 64 patients were divided into the control group $(n=32)$ and the observation group $(n=32)$ based on different therapeutic methods. There was no statistically significant difference in the general data of patients between the groups $(\mathrm{P}>0.05)$ (Table I). This study was approved by the Ethics Committee of Linyi Cancer Hospital. Signed informed consents were obtained from all participants before the study.

Therapeutic methods. In control group, chemotherapy was adopted: 5-fluorouracil (Shanghai Xudong Haipu Pharmaceutical Co., Ltd.; approval no: NMPN H31020593) was intravenously infused according to the standard of $400 \mathrm{mg} / \mathrm{m}^{2}$ and then pumped through peripheral veins for $46 \mathrm{~h}$ in accordance with the standard of $2400 \mathrm{mg} / \mathrm{m}^{2}$, once every 2 weeks. In observation group, surgical treatment was employed: After general anesthesia with tracheal intubation, Miles surgery was conducted, and patients with lymph node metastasis received unilateral or bilateral inguinal lymph node dissection.

Detection of indicators. Fasting venous blood (3-5 ml) was collected from the two groups of patients for separation and extraction of serum. Enzyme-linked immunosorbent assay (ELISA) was performed to measure the levels of IL-17, IL-23 and vascular endothelial growth factor (VEGF) using relevant kits (R\&D Systems) according to the instructions of the kits. Then, a microplate reader (Jiangsu Puyun Biotechnology Co., Ltd.) was used to read the optical density (OD) value at a wavelength of $450 \mathrm{~nm}$, and the concentration of IL-17, IL-23 and VEGF was calculated. The mononuclear cells were separated via Ficoll stratified liquid method, collected, incubated with anti-cluster of differentiation (CD3 (cat. no. AF1480), CD4 (cat. no. AF1792), CD8 (cat. no. AF1417) antibodies (Beyotime Institute of Biotechnology) in the dark at $4^{\circ} \mathrm{C}$ for $30 \mathrm{~min}$. Thereafter, a flow cytometer (BD Biosciences) was utilized for detection, and the value of $\mathrm{CD} 4^{+} / \mathrm{CD}^{+}$was calculated.

Evaluation of indexes. The changes in the patient serum IL-17, IL-23 and VEGF levels were compared before and after treatment. The immune function of patients was observed after treatment. The patients were followed up for 5 years, and the survival time and survival rate of different groups of patients were recorded.

Statistical analysis. Statistical Product and Service Solutions (SPSS) v19.0 software (SPSS Inc.) was employed for data processing. Measurement data were expressed as mean \pm standard deviation (mean \pm SD), and t-test was utilized for intergroup comparison. Comparison between multiple groups was done using two-way/mixed ANOVA test followed by post hoc test (Bonferroni). Enumeration data were expressed as ratio (\%) and subjected to $\chi^{2}$ test or Fisher's exact test. Kaplan-Meier method was applied for survival analysis. $\mathrm{P}<0.05$ was considered to indicate a statistically significant difference.

\section{Results}

Immune function after treatment in both groups of patients. After treatment, the levels of $\mathrm{CD}^{+}, \mathrm{CD}^{+}$and $\mathrm{CD}^{+} / \mathrm{CD}^{+}$were higher in the observation group than those in the control group, while the level of $\mathrm{CD}^{+}$was lower in the observation group than that in the control group $(\mathrm{P}<0.05$; Fig. 1 and Table II).

Serum IL-17 and IL-23 and VEGF levels of patients before and after treatment. The serum IL-17 and IL-23 and VEGF 

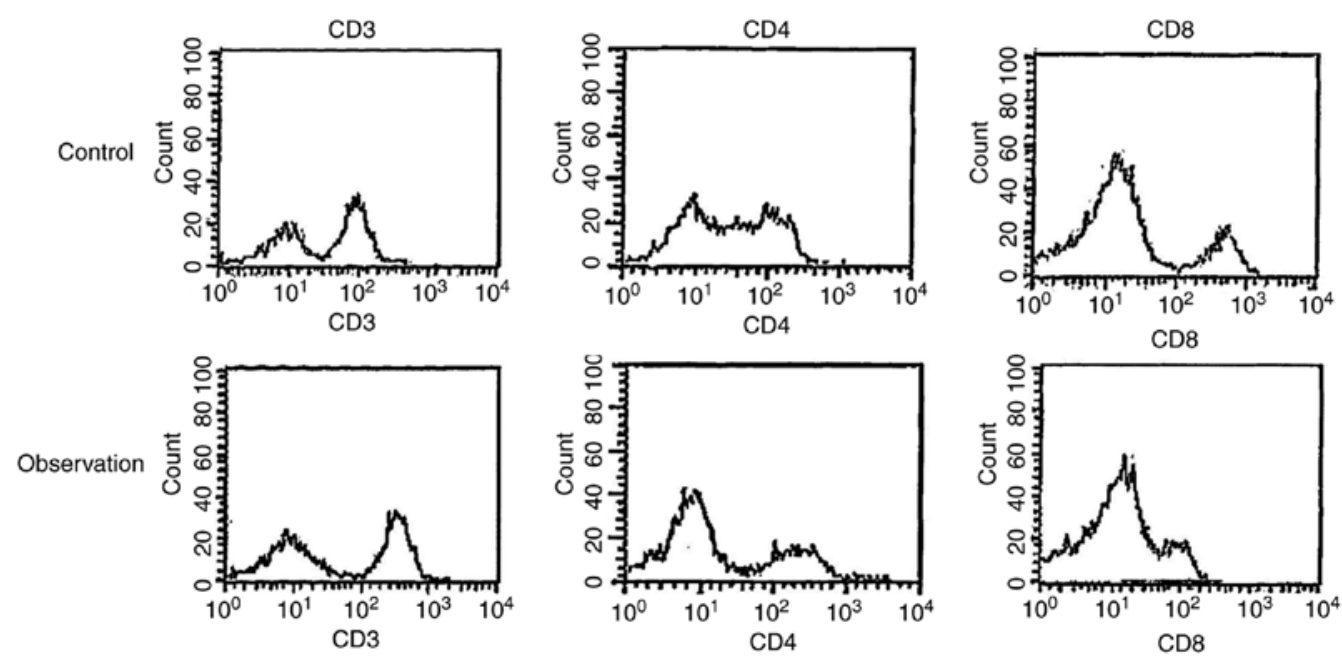

Figure 1. Representative images of flow cytometry plots in each group.

Table III. Comparison of IL-17 level between two groups of patients before and after treatment (ng/l).

\begin{tabular}{lccccc}
\hline Group & $\mathrm{n}$ & Before treatment & $\begin{array}{c}\text { At 4 weeks } \\
\text { after treatment }\end{array}$ & $\begin{array}{c}\text { At 6 weeks } \\
\text { after treatment }\end{array}$ & $\begin{array}{c}\text { At } 8 \text { weeks } \\
\text { after treatment }\end{array}$ \\
\hline Observation group & 32 & $193.85 \pm 13.43$ & $102.52 \pm 8.61^{\mathrm{a}}$ & $108.43 \pm 8.74^{\mathrm{a}}$ & $113.26 \pm 8.67^{\mathrm{a}}$ \\
Control group & 32 & $193.87 \pm 13.58$ & $163.37 \pm 11.78^{\mathrm{a}}$ & $158.18 \pm 9.67^{\mathrm{a}}$ & $142.08 \pm 9.53^{\mathrm{a}}$ \\
P-value & & 0.813 & $<0.001$ & $<0.001$ & $<0.001$ \\
\hline
\end{tabular}

${ }^{\mathrm{a}} \mathrm{P}<0.05$ vs. before treatment.

Table IV. Comparison of IL-23 level between two groups of patients before and after treatment $(\mu \mathrm{g} / \mathrm{l})$.

\begin{tabular}{|c|c|c|c|c|c|}
\hline Group & $\mathrm{n}$ & Before treatment & $\begin{array}{c}\text { At } 4 \text { weeks } \\
\text { after treatment }\end{array}$ & $\begin{array}{c}\text { At } 6 \text { weeks } \\
\text { after treatment }\end{array}$ & $\begin{array}{l}\text { At } 8 \text { weeks } \\
\text { after treatment }\end{array}$ \\
\hline Observation group & 32 & $3.89 \pm 0.63$ & $1.03 \pm 0.35^{\mathrm{a}}$ & $1.21 \pm 0.34^{\mathrm{a}}$ & $1.28 \pm 0.37^{\mathrm{a}}$ \\
\hline Control group & 32 & $3.86 \pm 0.68$ & $2.84 \pm 0.56$ & $2.59 \pm 0.53$ & $2.13 \pm 0.58$ \\
\hline P-value & & 0.859 & $<0.001$ & $<0.001$ & $<0.001$ \\
\hline
\end{tabular}

${ }^{\mathrm{a}} \mathrm{P}<0.05$ vs. before treatment.

Table V. Comparison of VEGF level between two groups of patients before and after treatment (mg/l).

\begin{tabular}{|c|c|c|c|c|c|}
\hline Group & $\mathrm{n}$ & Before treatment & $\begin{array}{c}\text { At } 4 \text { weeks } \\
\text { after treatment }\end{array}$ & $\begin{array}{c}\text { At } 6 \text { weeks } \\
\text { after treatment }\end{array}$ & $\begin{array}{l}\text { At } 8 \text { weeks } \\
\text { after treatment }\end{array}$ \\
\hline Observation group & 32 & $285.85 \pm 9.13$ & $183.02 \pm 8.61^{\mathrm{a}}$ & $185.63 \pm 7.34^{\mathrm{a}}$ & $191.36 \pm 6.37^{\mathrm{a}}$ \\
\hline Control group & 32 & $286.72 \pm 9.18$ & $249.64 \pm 8.78^{\mathrm{a}}$ & $234.52 \pm 7.47^{\mathrm{a}}$ & $209.75 \pm 6.43^{\mathrm{a}}$ \\
\hline P-value & & 0.857 & $<0.001$ & $<0.001$ & $<0.001$ \\
\hline
\end{tabular}

${ }^{\mathrm{a}} \mathrm{P}<0.05$ vs. before treatment.

levels of patients markedly declined in the groups at 4,6 and 8 weeks after treatment, and the decrease in the observation group was more evident $(\mathrm{P}<0.05$; Tables III-V).
Comparison of recurrence rate and survival of patients between the groups. Observation group exhibited longer average survival time, a clearly lowered recurrence rate and 
Table VI. Comparison of 5-year follow-up between two groups of patients.

\begin{tabular}{lcccc}
\hline Group & $\mathrm{n}$ & 5-year survival rate [n (\%)] & Recurrence rate [n (\%)] & Average survival time [month(s)] \\
\hline Observation group & 32 & $8(25.00)$ & $20(62.50)$ & $22.76 \pm 6.74$ \\
Control group & 32 & $1(3.13)$ & $30(93.75)$ & $12.83 \pm 5.63$ \\
$\chi^{2 / t}$ & & - & 7.406 & 6.427 \\
P-value & & 0.026 & 0.006 & $<0.001$ \\
\hline
\end{tabular}

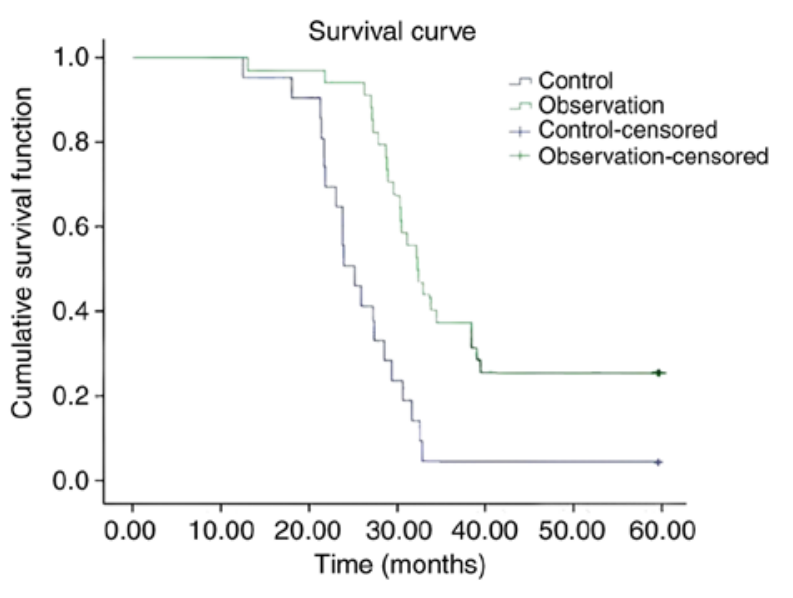

Figure 2. Patient survival curve. Based on the analysis through Kaplan-Meier, $\mathrm{P}<0.05$.

a dramatically raised 5-year survival rate in comparison with the control group $(\mathrm{P}<0.05$; Table VI and Fig. 2).

\section{Discussion}

Malignant melanoma, a malignancy with high malignant degree, occurs in organs such as the liver, skin, kidneys, eyes and uterus and is mainly characterized by over proliferation of melanocytes $(5,12)$. Moreover, malignant melanoma in the skin ascribes to excessive ultraviolet irradiation, but, there is no ultraviolet irradiation in ARMM, and its pathogenesis is not fully understood. It is generally assumed that ARMM occurs because of the combined effects of environmental and genetic factors (13). ARMM is prevalent in middle-aged and elderly people, and its incidence rate is overtly higher in women than that in men (14). In clinical practice, the treatment of ARMM aims to prolong the survival time of patients as far as possible, and radiotherapy, chemotherapy and surgery are mainly employed, of which surgery is currently deemed as the preferred therapeutic option (15).

Patients with ARMM often suffer immune dysfunction (16). $\mathrm{CD}^{+}$can reflect the level of all $\mathrm{T}$ lymphocytes in the body, and $\mathrm{CD}^{+}$can positively modulate the immunity (6). $\mathrm{CD}^{+}$is able to kill and destroy cells, which can inhibit $\mathrm{CD}^{+}$and aggravate the immune dysfunction of patients (17). It was uncovered in the present study that the observation group had elevated $\mathrm{CD}^{+}, \mathrm{CD}^{+}$and $\mathrm{CD} 4^{+} / \mathrm{CD}^{+}$ levels and lower $\mathrm{CD}^{+}$level in comparison with the control group. This is because surgical treatment can effectively remove the tumor, control the metastasis of mesenteric lymph nodes, rapidly reduce the tumor load, improving the impaired immune status.

Inflammatory response, an important part of body immunity, occurs due to the stimulation of both internal and external environment (18). Inflammation has a close correlation with malignant tumors, which is capable of providing a favorable environment for the development of tumors and promoting their progression. IL-23, a member of the IL family, is secreted by phagocytes, binding to cell surface membrane receptor complexes to activate the $\mathrm{NF}-\kappa \mathrm{B}$ signaling pathway and exerting its functions of regulating immune surveillance and breaking immune balance, thus inducing tumors (19). IL-17, also a member of the IL family, is a pro-inflammatory cytokine, which is one of the early promoters of the inflammatory response amplifying the inflammatory response (20). The results of this study showed that the serum IL-17 and IL-23 levels of patients markedly declined in the two groups after treatment, and the decrease in the observation group was more evident $(\mathrm{P}<0.05)$. This may be because the surgical treatment of tumor removal can relieve tumor load, improve immune status and stimulate $\mathrm{T}$ cells to exert anti-inflammatory effects, thus down-regulating the expression levels of IL-17 and IL-23.

VEGF, a member of platelet-derived growth factor family, plays a vital role in the development and progression of ARMM, which accelerates the neovascularization at tumor sites and promotes the growth of tumors, strengthening invasiveness of the tumor and letting it break through the intestinal wall to invade adjacent tissues, and thus resulting in regional lymph node metastasis and even metastasis to distant organs i.e. the liver, lungs, bones and the brain (10). In the present study, the serum VEGF level markedly declined in both groups after treatment, with a more evident decrease in the observation group $(\mathrm{P}<0.05)$. Surgical treatment down-regulates expression of VEGF, blocks tumor angiogenesis, and inhibits metastasis, with more pronounced short-term curative effects.

ARMM progresses rapidly. It may be cured by surgery, but the recurrence rate is still high, the patient prognosis is poor, and the survival time remains short. The results of the present study revealed that the recurrence rate was lower in the observation group than in the control group, while the survival time and survival rate were distinctly better in the observation group than those in the control group $(\mathrm{P}<0.05)$. This is because surgical treatment can effectively resect both the tumor and the affected surrounding adjacent tissues, thus achieving a more thorough treatment effect, and it can control the lymph node or distant metastasis to a certain extent, thereby reducing the recurrence rate and improving the survival rate of patients. 
In conclusion, surgical treatment applied in ARMM achieves better efficacy in comparison with non-surgical treatment, lowering the serum IL-17 and IL-23 levels, improving patient prognosis, reducing recurrence rate and prolonging patient survival time, which is of positive significance in clinic. Unfortunately, the comparison of these target parameters between low- and high-grade of ARMM in the control and observation groups was not included in the present study. We would like to further investigate this topic in our next work.

\section{Acknowledgements}

Not applicable.

\section{Funding}

No funding was received.

\section{Availability of data and materials}

All data generated or analyzed during this study are included in this published article.

\section{Authors' contributions}

$\mathrm{MH}$ and $\mathrm{ZZ}$ designed the study and performed the experiments. MH and WT collected the data. ZZ and WT analyzed the data. $\mathrm{MH}$ and $\mathrm{ZZ}$ wrote the manuscript. All authors read and approved the final manuscript.

\section{Ethics approval and consent to participate}

The present study was approved by the Ethics Committee of Linyi Cancer Hospital. Signed informed consents were obtained from the patients.

\section{Patients consent for publication}

Not applicable.

\section{Competing interests}

The authors declare that they have no competing interests.

\section{References}

1. Latteri S, Teodoro M, Malaguarnera M, Mannino M, Currò G and La Greca G: Abdominal perineal resection or Wilde local excision in primary anorectal malignant melanoma. Case report and review. Ann Med Surg (Lond) 19: 74-77, 2017.

2. Tokuhara K, Nakatani K, Tanimura H, Yoshioka K, Kiyohara T and Kon M: A first reported case of metastatic anorectal amelanotic melanoma with a marked response to anti-PD-1 antibody nivolumab: A case report. Int J Surg Case Rep 31: 188-192, 2017.
3. Zaiem F and Alrifai A: Anorectal malignant melanoma presenting as acute pancreatitis. Am J Med Sci 354: 327-328, 2017.

4. Ohta R, Inoue $T$, Goto $M$, Tachimori $Y$ and Sekikawa $K$ : Combined laparoscopic abdomino-endoscopic perineal total mesorectal excision for anorectal malignant melanoma: A case report. Int J Surg Case Rep 44: 135-138, 2018.

5. Seo KI, Moon W, Kim SE, Park MI and Park SJ: Malignant melanoma of the anus found during routine colonoscopy in ulcerative colitis. Korean J Gastroenterol 69: 368-371, 2017.

6. Jesinghaus M, Steiger K, Slotta-Huspenina J, Drecoll E, Pfarr N, Meyer P, Konukiewitz B, Bettstetter M, Wieczorek K, Ott K, et al: Increased intraepithelial $\mathrm{CD}^{+} \mathrm{T}-$ lymphocytes and high PD-L1 expression on tumor cells are associated with a favorable prognosis in esophageal squamous cell carcinoma and allow prognostic immunogenic subgrouping. Oncotarget 8: 46756-46768, 2017.

7. Wang L and Shen Y: Imbalance of circulating T-lymphocyte subpopulation in gastric cancer patients correlated with performance status. Clin Lab 59: 429-433, 2013.

8. Karabulut M, Usul AC, Serimez M and Karabulut S: Serum IL-17 levels can be diagnostic for gastric cancer. J BUON 24: 1601-1609, 2019.

9. Tang WJ, Tao L, Lu LM, Tang D and Shi XL: Role of T helper 17 cytokines in the tumour immune inflammation response of patients with laryngeal squamous cell carcinoma. Oncol Lett 14: 561-568, 2017.

10. Treskova I, Topolcan O, Windrichova J, Simanek V, Slouka D, Treska V and Kucera R: OPG, OPN, EGF and VEGF levels at individual Breslow score stages in malignant melanoma. Anticancer Res 38: 4907-4911, 2018.

11. Kumar U and Singhal U: Anorectal melanoma: An unusual cause of rectal bleeding. J Clin Diagn Res 11: D12-D13, 2017.

12. Yang J, Xiao P, Sun J and Guo L: Anticancer effects of kaempferol in A375 human malignant melanoma cells are mediated via induction of apoptosis, cell cycle arrest, inhibition of cell migration and downregulation of $\mathrm{m}-\mathrm{TOR} / \mathrm{PI} 3 \mathrm{~K} / \mathrm{AKT}$ pathway. J BUON 23: 218-223, 2018.

13. Ranjith S, Muralee M, Sajeed A, Arun PM, Cherian K, Nair CK, Augustine P and Ahamed I: Anorectal melanoma: Experience from a tertiary cancer care centre in South India. Ann R Coll Surg Engl 100: 185-189, 2018.

14. Bulut N, Dagistanli S, Yilmaz B and Atay OF: Surgical approach to anorectal melanoma with PET-CT staging: A case report. Surg J (NY) 3: e177-e180, 2017.

15. Cai ED and Kim J: Identification of novel targetable mutations in metastatic anorectal melanoma by next-generation sequencing. JAAD Case Rep 3: 539-541, 2017.

16. Virgilio E, Mercantini P, Santangelo G, Canali G, Peritore V and Balducci G: Anorectal melanoma: A rare aggressive type of melanoma. Anz J Surg 87: 421-422, 2017.

17. Sousa IG, Do AM, Simi KC, Bezerra MA, Andrade RV, Maranhao AQ and Brigido MM: MicroRNA expression profiles in human $\mathrm{CD} 3(+) \mathrm{T}$ cells following stimulation with anti-human CD3 antibodies. BMC Res Notes 10: 124, 2017.

18. Hofmann H: A foot tumour as late cutaneous lyme borreliosis: A new entity or a variant of an inflammatory proliferative reaction to borrelia burgdorferi? Br J Dermatol 177: 906-907, 2017.

19. Nie W, Yu T, Sang Y and Gao X: Tumor-promoting effect of IL-23 in mammary cancer mediated by infiltration of M2 macrophages and neutrophils in tumor microenvironment. Biochem Biophys Res Commun 482: 1400-1406, 2017.

20. Amicarella F, Muraro MG, Hirt C, Cremonesi E, Padovan E, Mele V, Governa V, Han J, Huber X, Droeser RA, et al: Dual role of tumour-infiltrating T helper 17 cells in human colorectal cancer. Gut 66: 692-704, 2017. 